\title{
Evaluation of the coefficient of performance of an air source heat pump unit and an air to water heat pump
}

\author{
S. Tangwe* ${ }^{\star}$, K. Kusakana \\ Department of Electrical, Electronic and Computer Engineering, Faculty of Engineering, Built Environment and \\ Information Technology, Central University of Technology, Free State, South Africa
}

\begin{abstract}
Air source heat pump (ASHP) water heaters are efficient devices for sanitary hot water heating. The coefficient of performance (COP) of the air to water heat pump (AWHP) is constantly lower than that of the corresponding ASHP unit. The study focused on determining the COP of both the ASHP unit and the AWHP. This was achieved by the implementation of both experimental and simulation methods, with the help of a data acquisition system and the REFPROP software. The system comprised of a $1.2 \mathrm{~kW}$ split type ASHP unit and a $150 \mathrm{~L}$ high pressure geyser. A power meter, flow meters, temperature sensors, pressure sensors, ambient temperature and relative humidity sensor were installed at precise locations on the split type AWHP. Controlled volumes of 150, 50 and $100 \mathrm{~L}$ were drawn off from the AWHP during the morning, afternoon and evening for a year. The average COP for the summer and winter, in terms of the input electrical and output thermal energies of the AWHP were 3.02 and 2.30. The COPs of the ASHP unit, in terms of the change in the enthalpies of the refrigerant at the inlet and the outlet of the condenser and the evaporator, were 3.52 and 2.65 respectively. The study showed that the difference between the COP of the ASHP unit and that of the AWHP could be ascribed to the electrical energy consumed by the fan and the water circulation pump during the vapour compression refrigeration cycles. The work provides an energy optimisation opportunity to the manufacturers of this technology, helping to enhance the efficiency and COP of ASHP water heaters.
\end{abstract}

Keywords: vapour compression refrigeration cycle, coefficient of performance, energy optimisation, data acquisition system

\section{Highlights}

1. The COPt of the ASHP unit was higher than the COPe of the AWHP.

2. The COPe of the AWHP was the ratio of the input electrical energy consumed and the output thermal energy gained by the stored water.

3. The COPt of the ASHP unit was enthalpies-dependent and a function of inlet and outlet enthalpies of the evaporator and condenser.

4. The inlet and outlet refrigerant temperatures profiles of the condenser confirmed thermal energy dissipation.

Journal of Energy in Southern Africa 32(1): 27-40

DOI: https://dx.doi.org/10.17159/2413-3051/2021/v32i1a7935

Published by the University of Cape Town ISSN: 2413-3051 https://journals.assaf.org.za/jesa

This work is licensed under a Creative Commons Attribution-ShareAlike 4.0 International Licence

Sponsored by the Department of Science and Innovation

Corresponding author: Email: Istephen@cut.ac.za 


\author{
Abbreviations \\ ASHP Air source heat pump \\ COP Coefficient of performance \\ COPe COP of AWHP based on the output thermal energy gained and input electrical energy consumed by \\ the ASHP water heater \\ COPt COP of ASHP unit based on the difference in enthalpies at the inlet and outlet of the heat exchangers \\ (condenser and evaporator) of the ASHP unit \\ EE Electrical energy consumed in kWh \\ TE Thermal energy gained in kWh \\ $\mathrm{p} \quad$ Average power consumed in $\mathrm{kW}$ \\ Pevpi Pressure of the refrigerant at the inlet of the evaporator in $\mathrm{MPa}$ \\ Pevpo Pressure of the refrigerant at the outlet of the evaporator in $\mathrm{MPa}$ \\ Pconi Pressure of the refrigerant at the inlet of the condenser in $\mathrm{MPa}$ \\ Pcono Pressure of the refrigerant at the outlet of the condenser in $\mathrm{MPa}$ \\ Tevpi Temperature of the refrigerant at the inlet of the evaporator in ${ }^{\circ} \mathrm{C}$ \\ Tevpo Temperature of the refrigerant at the outlet of the evaporator in ${ }^{\circ} \mathrm{C}$ \\ Tconi Temperature of the refrigerant at the inlet of the condenser in ${ }^{\circ} \mathrm{C}$ \\ Tcono Temperature of the refrigerant at the outlet of the condenser in ${ }^{\circ} \mathrm{C}$ \\ $\mathrm{m} \quad$ Mass of water heated in $\mathrm{kg}$ \\ c Specific heat capacity of water in $\mathrm{kJ} / \mathrm{kg}^{\circ} \mathrm{C}$ \\ $\mathrm{Ti}$ Temperature of water at the inlet of the ASHP \\ To Temperature of water at the outlet of the ASHP \\ VCRC Vapour compression refrigeration cycle
}

\section{Introduction}

Sanitary hot water heating is associated with high electrical energy consumption [1]. In South Africa, it contributes up to $30-50 \%$ of the monthly electricity cost of households, and the majority of hot water heating is achieved through inefficient geysers [2]. Geysers are often retrofitted with air source heat pump (ASHP) units and the resulting device is called the AWHP. The striking characteristic that gives their excellent performance is the coefficient of performance (COP), and the device is classified as a renewable energy technology as well as an energy-efficient technology [3; 4]. The COP of the ASHP water heater ranges from 2 to 4 , depending on the ambient temperature, the system design, and the hot water heating loads $[5,6,7]$. The operational performance of the ASHP water heaters has been reported to be more efficient in summer than in winter, attributable to the favourable ambient temperature [8]. ASHP water heaters are commonly categorised into the split and integrated types. In the split type, the ASHP unit and the hot water storage tank are connected by copper pipes with the unit situated below the tank. Conversely, the integrated type ASHP water heater is a compact design with the ASHP unit located above the tank while the condenser is immersed in the tank [10]. Extensive research has shown that the integrated type performs better when the systems are of the same input electrical power and tank size (both types are without auxiliary electric backup) $[11,12]$. Furthermore, the integrated type ASHP water heater is prom to failure, and the system is more unstable than the split type. Moreover, the integrated type experiences lower standby losses than the split type [13].

It is important to mention that studies have been conducted on the energy performance and COP of heat pump systems other than ASHP water heaters. De Swardt and Meyer [19] compared the performance of a ground source heat pump integrated into a municipal water reticulation system with a conventional ASHP for heating and cooling in South Africa. Urchueguía et al. [20] compared the energy performance of a ground coupled water-to-water heat pump system to an air-to-water heat pump system, specifically for heating and cooling in a typical air conditioning space on the Mediterranean. The authors found that the ground coupled heat pump system performed more efficiently than the ASHP system, and recorded a favourable payback period. The energy COP for an ASHP couple with a horizontal earth-to-air heat exchanger was determined using both numerical and experimental methods [21]. A detailed review on the performance of ASHP systems assisted by solar thermal source, photovoltaic source and combined thermal and photovoltaic sources has been conducted, to ascertain the energy performances of the different types of ASHP systems [22].

Although ASHP water heaters are efficient hot water heating devices, the COP can be improved if the ASHP water heater is configured to operate within the range of the Carnot's COP of an ASHP unit 
[14]. The present study investigated and analysed the input electrical and useful output thermal energy of the AWHP. It also determined the change in enthalpy of the refrigerant at the inlet and outlet of the heat exchangers (evaporator and condenser) of the ASHP unit when 50,100 and $150 \mathrm{~L}$ of hot water were drawn off. The findings from the study can assist in predicting the techno-economic performance and energy management opportunities in ASHP water heaters.

\section{Fundamentals of the heat pump operations}

An ideal ASHP water heater transfers thermal energy during its vapour compression refrigeration cycle (VCRC) from the ambient air, to heat water in the storage tank. The process may lead to cooling and dehumidification of the air to a certain degree based on the ambient condition. Figure 1 provides a schematic diagram of the components that are involved in the VCRC of a typical ASHP water heater.

A salient and better understanding of the refrigeration cycle of the heat pump water heater was given by Ashdown (2004) and Sinha and Dysarkar (2008) $[15,16]$. During a VCRC, aero-thermal energy gained by the evaporator is absorbed by the refrigerant R417A (liquid and vapour coexist) to change the phase of the liquid portion to vapour (latent heat) and also the refrigerant gains sensible thermal energy. The process is relatively isobaric and occurs between points 4 and 1 in Figure 1 . The difference in pressure between the suction and the discharge end enables the refrigerant vapour (dry, low-temperature and pressure refrigerant vapour) to flow to the compressor. In the compressor, the vapour is compressed to a super-heated vapour and exits along the discharge line. The process is thermodynamically described as isenthropic, under a prevailing idealized condition and occurs along 12 in Figure 1. As the super-heated refrigerant vapour flows into the condenser, the refrigerant is condensed and a saturated refrigerant liquid is formed. The thermal energy dissipated is used to heat the water flowing through the inner tube of the condenser. Along 2-3 in Figure 1 the temperature of the super-heated vapour drops, resulting in the formation of a subcool vapour, which in turn loses its thermal energy to become a saturated refrigerant liquid. The process is referred to as isobaric condensation. At the expansion valve, the pressure and temperature decrease and the saturated refrigerant liquid becomes a low-pressure liquid refrigerant. The process is isenthalpic, under idealized conditions and occurs along 3-4 in Figure 1.

\section{Calculation and theory}

The input electrical energy consumed by the ASHP water heater during a VCRC is the product of the average electrical power consumed and the time taken, as given in Equation 1.

$$
\mathrm{EE}=\mathrm{pt}
$$

where EE = elecrical energy consumed by the ASHP water heater; $p=$ electrical power consumed by the heater; and $\mathrm{t}=$ time taken during the heating cycle.

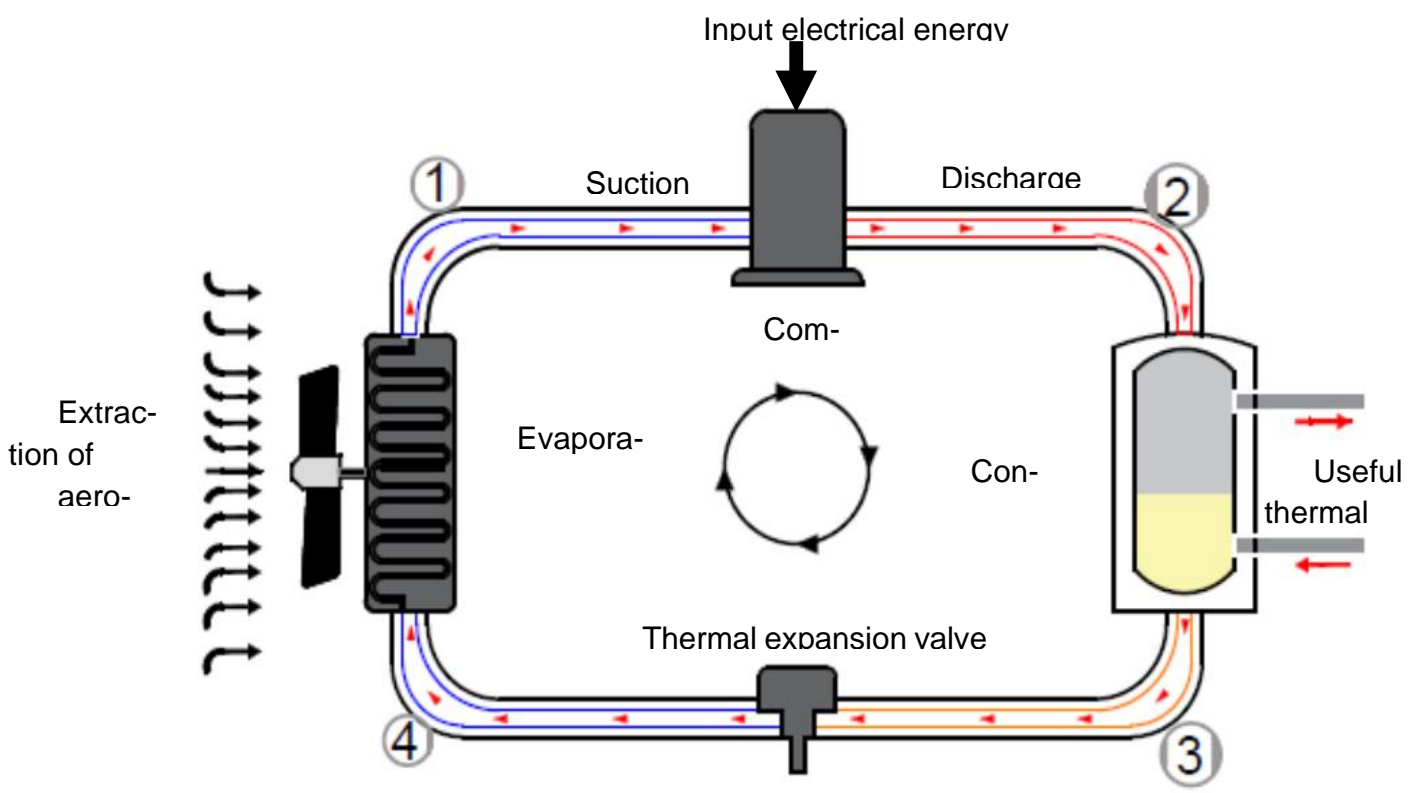

Figure 1: A schematic block diagram of the main components of an ASHP. 
The useful output thermal energy gained by the stored hot water is the product of the mass of water heated by the ASHP unit, the specific heat capacity of water and the difference in the temperature of water at the outlet and the inlet of the ASHP unit, during the VCRC, given in Equation 2.

$$
\mathrm{TE}=\operatorname{mc}(\mathrm{To}-\mathrm{Ti})
$$

where TE = thermal energy gained by stored water in the tank of the ASHP water heater; $m$ = mass of water heated; $c$ = specific heat capacity of water; To = temperature of water at the outlet of ASHP unit; and $\mathrm{Ti}=$ temperature of water at the inlet of ASHP unit.

The COP of the AWHP with respect to the input and output energies is defined as the ratio of the useful output thermal energy gained by the stored water and the input electrical energy consumed by the unit, given in Equation 3.

$$
\mathrm{COPe}=\frac{\mathrm{TE}}{\mathrm{EE}}
$$

where $\mathrm{COPe}=\mathrm{COP}$ of AWHP in terms of output energy and input energy; TE = thermal energy gained by stored water in the tank; and EE = electrical energy consumed by the AWHP.

The COP of the ASHP unit relating to the changes in enthalpies is defined as the ratio of the change in the enthalpy of the refrigerant at the inlet and the outlet of the condenser to the difference between the change in the enthalpy of the refrigerant at the inlet and outlet of the condenser and the evaporator. The relationship is explicitly shown in Equation 4. The enthalpies are obtained from the saturation liquid-vapour table generated by the simulation with the REFPROP software, based on the experimental measured values of the temperatures and pressures of the refrigerant at the inlet and outlet of the heat exchangers of the ASHP unit during VCRC.

$$
\mathrm{COPt}=\frac{\text { hconi-hcono }}{\text { (hconi-hcono })-(\text { hevpo-hevpi })}
$$

where COPt = COP of ASHP unit in terms of enthalpies at the inlet and outlet of the heat exchangers; hconi = enthalpy of refrigerant at the inlet of the condenser; hcono = enthalpy of refrigerant at the outlet of the condenser; hevpi = enthalpy of refrigerant at the inlet of the evaporator; and hevpo = enthalpy of refrigerant at the outlet of the evaporator.

\section{Objectives}

The objectives of the study are broken down into three tasks:

i. To investigate and analyse the input electrical energy consumed and the useful output thermal energy gained by the AWHP. ii. To determine the change in enthalpy of the refrigerant at the inlet and outlet of the heat exchangers (evaporator and condenser) of the ASHP unit.

iii. To evaluate the COP of the ASHP unit and the COP of the AWHP, due to the specific volumes of hot water drawn off from the tank of the split type AWHP.

\section{Materials and methods \\ 5.1 Materials}

The materials used in the study are presented in Table 1.

Table 1: List of the devices and sensors.

\begin{tabular}{clc}
\hline Items & \multicolumn{1}{c}{ Materials } & Quantities \\
\hline 1 & $1.2 \mathrm{~kW}$ split type ASHP unit & 1 \\
2 & $\begin{array}{l}\text { 150 L, 3 kW high pressure } \\
\text { geyser }\end{array}$ & 1 \\
3 & Hot water volume control & 1 \\
& valve & \\
4 & Ambient temperature and & 1 \\
& relative humidity sensor & \\
5 & Power meter & 1 \\
6 & Temperature sensors & 11 \\
7 & Pressure sensors & 4 \\
8 & Flow meters & 2 \\
9 & Hot water collecting drum & 1 \\
10 & Data loggers & 2 \\
11 & REFPROP software & 1 \\
12 & Hoboware pro software & 1 \\
13 & Weather and waterproof & 1 \\
& enclosure & \\
\hline
\end{tabular}

\subsection{Methods}

The methods implemented in the study were divided into five procedures as follows:

i. The design and installation of the split type AWHP and the configuration and installation of the sensors and transducers.

ii. The execution of the hot water drawn off $(50$, 100 and $150 \mathrm{~L}$ ) during the time of use, for both summer and winter periods.

iii. Analysis of the power consumed and ambient condition (ambient temperature and relative humidity) profiles as well as the power consumed and the temperature profiles.

iv. Analysis of the COP of the AWHP for both the summer and winter periods, in terms of the input electrical energy consumed and the output thermal energy gained. 
v. Analysis of the COP of the ASHP unit for both the summer and winter periods, in relation to the enthalpy change between the inlet and the outlet of the evaporator and the condenser.

\subsection{Experimental setup}

Figure 2 shows the schematic diagram of the installed split type AWHP in the outdoor space of the renewable energy laboratory at the Central University of Technology, Free State, South Africa. The AWHP comprised of $1.2 \mathrm{~kW}$ ASHP unit with a $150 \mathrm{~L}$, $3 \mathrm{~kW}$ geyser. The element of the geyser was disabled and it acted as a storage tank while retrofitted with the ASHP unit. The ASHP unit was positioned below the geyser and the devices were connected by reticulation copper pipes, as shown in Figure 2. The ASHP unit was embedded with a $90 \mathrm{~W}$ water circulation pump that provided the required water pressure. The pressure exerted by the pump allowed the circulation of water between the geyser and the condenser in the ASHP during the VCRC. The ASHP unit contained a propeller axial fan of $70 \mathrm{~W}$ at the rear end of the evaporator. The fan helped to create a force convection of the ambient air in the vicinity of the ASHP unit. The force convection increased the rate of the extraction of the aero-thermal energy into the refrigerant at the evaporator during the VCRC.

Figure 3 shows the schematic layout of the split type ASHP water heater and the installed sensors.
The ambient temperature and relative humidity sensor (Ta/RH) was installed in the vicinity of the ASHP water heater and it measured both the ambient temperature and the relative humidity. A power meter, with an inherent logging capability, was installed on the power line, supplying electricity to the ASHP unit. The power meter measured the input electrical power consumed by the heat pump water heater. Two flow meters (V and Vd) were installed, one close to the inlet of the ASHP unit and the other at a position on the copper pipe in proximity to the hot water discharge end of the geyser. The flow meters measured the volume of hot water heated by the unit and the volume of hot water drawn off from the storage tank. Eleven temperature sensors were installed at different locations on the installed ASHP water heater. The temperature sensor T1 measured the temperature of the incoming cold water from the mains into the storage tank of the ASHP water heater. The temperature sensor T2 measured the temperature of the air around the vicinity of the ASHP's evaporator. The temperature sensor T3 measured the temperature of the hot water discharged from the storage tank into the collecting drum. The temperature sensors T4 and T5 measured the temperature of the water at the inlet and the outlet of the ASHP unit. The temperature sensors T6 and T7 measured the temperature of the refrigerant at the suction and discharge ends of the compressor contained in the ASHP. The temperature sensors T8 and T9 measured the temperature

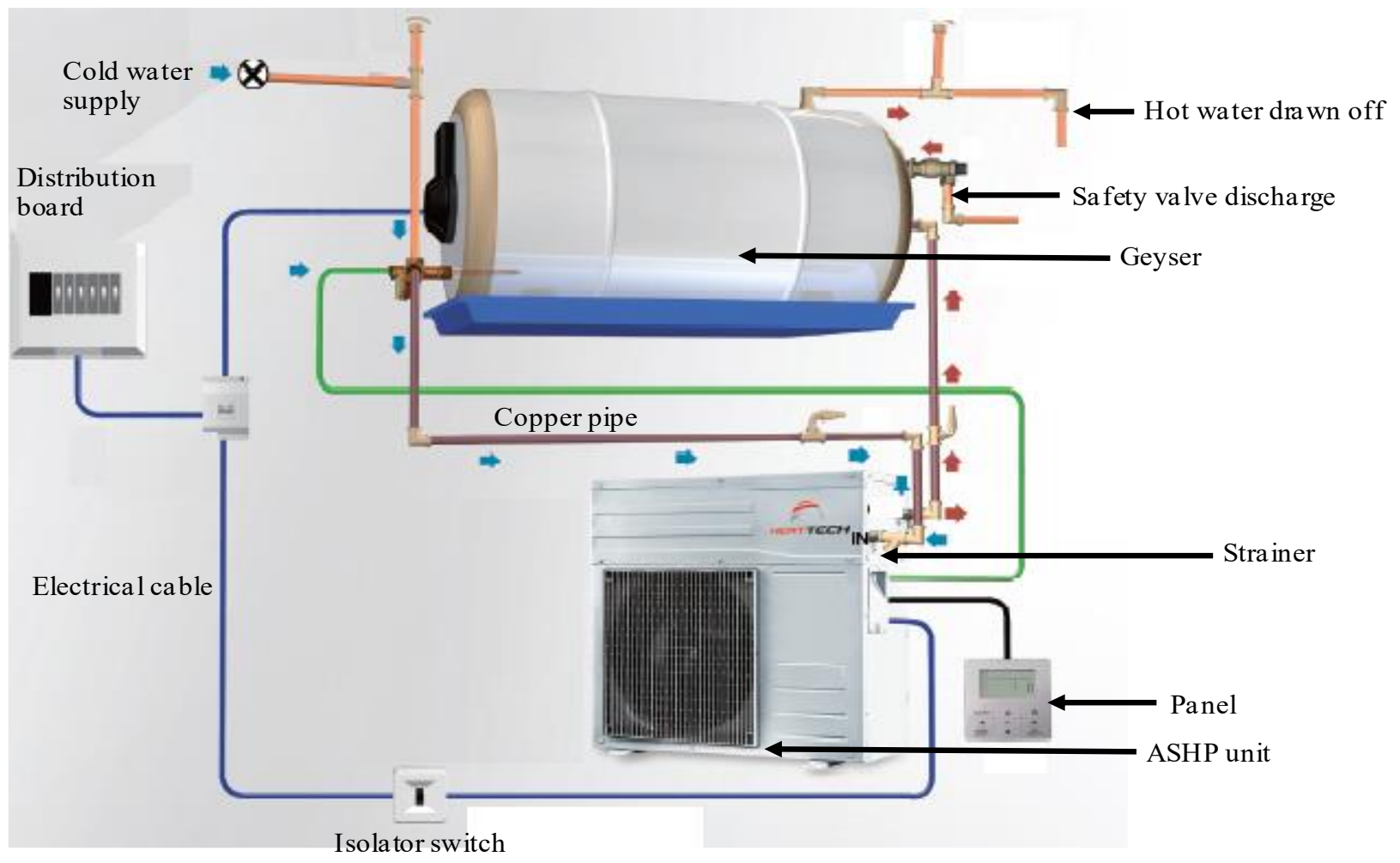

Figure 2: Schematic diagram of the installed split type ASHP water heater. 


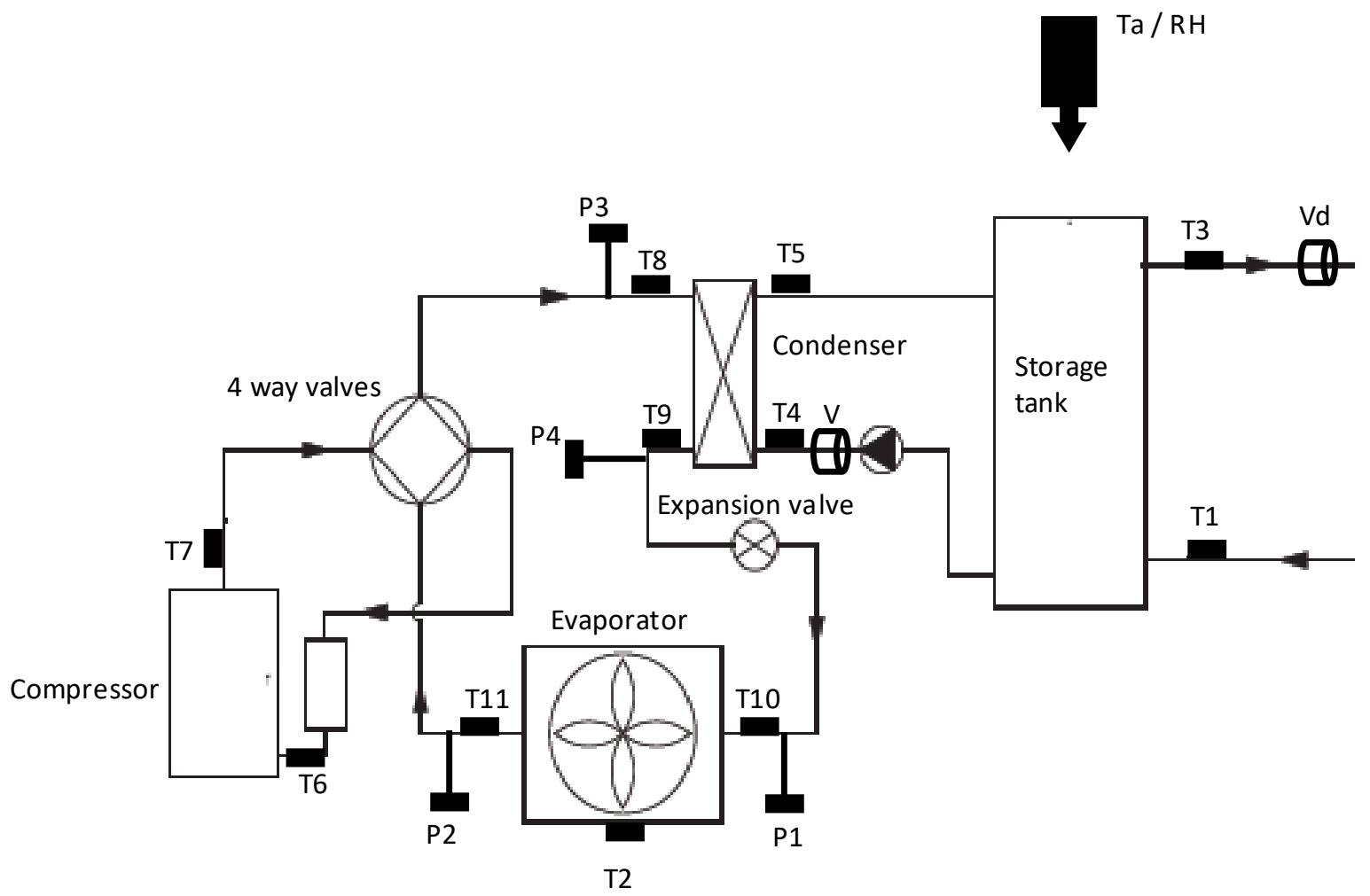

Figure 3: Schematic layout of the installed split type ASHP water heater and the sensors.

of the refrigerant at the inlet and the outlet of the condenser contained in the ASHP. Finally, the temperature sensors T10 and T11 measured the temperature of the refrigerant at the outlet and the inlet of the ASHP's evaporator. The pressure transducers P1 and P2 measured the pressure of the refrigerant at the inlet and the outlet of the ASHP's evaporator. The pressure transducers P3 and P4 measured the pressure of the refrigerant at the inlet and the outlet of the ASHP's condenser. All the sensors and the transducers were accommodated in two U30 no-remote-communication data-loggers, each comprising 15 logging channels. All the sensors and transducers were products of the Hobo Corporation and were compatible with the U30 no-remote-communication data-loggers. The sensors and transducers were configured by the Hoboware Pro software, to $\log$ in every five-minute interval throughout the experiment [3]. The data acquisition system was enveloped by a waterproof sheath to protect it from damage by interference from solar radiation and other unfavourable ambient conditions. The enthalpy measurements were obtained from the REFPROP software, upon running the simulation of the saturated liquid and vapour table for the refrigerant R417A. The generated saturated refrigerant table was based on both the measured temperatures and pressures of the refrigerant (R417A) at the inlet and the outlet of the evaporator and condenser during the VCRC $[17 ; 18]$.

\section{Results and discussion} 6.1. A typical day demand and ambient weather profiles due to hot water drawn off

The profiles of the power consumed by the AWHP and the ambient temperature and relative humidity after 50, 100 and $150 \mathrm{~L}$ of hot water drawn off were analysed. The observation was emphasised on the profiles of the demand of the AWHP and the ambient temperature and relative humidity, during the VCRC, due to the specific controlled volumes of hot water drawn off.

\subsubsection{Power consumed and ambient weather profiles after $50 \mathrm{~L}$ hot water drawn off}

Figure 4 shows that it took 50 minutes for the stored water to attain its set point temperature $\left(55.0^{\circ} \mathrm{C}\right)$ after $50 \mathrm{~L}$ of hot water was drawn off from the storage tank. The average temperature of the incoming cold water replacing the water drawn off was $23.0^{\circ} \mathrm{C}$. The electrical power consumed during the heating cycle, as depicted in Figure 4, shows that from 10 to 40 minutes after the start of the heating cycles there were negligible variations and the average was $1.24 \mathrm{~kW}$. There was a noticeable rise and fall in the electrical power consumed during the first and last 10 minutes of the heating cycles, due to the time delay encountered at the start up, before the electric induction motors in the fan and the compressor could attain their constant power. In addition, there existed a time difference between 
the time the hot water attained the set point temperature and the time taken by the electric motors in the fan and the compressor to stop operating. It can be observed that both the ambient temperature and relative humidity were fairly constant and the averages were $23.4^{\circ} \mathrm{C}$ and $60.53 \%$ respectively, throughout the heating cycles.

\subsubsection{Power consumed and ambient weather} profiles after 100 L hot water drawn off

Figure 5 shows that it took 70 minutes for the stored water to reach the set point temperature $\left(55.0^{\circ} \mathrm{C}\right)$, after $100 \mathrm{~L}$ of hot water was drawn from the storage tank. The average temperature of the cold water replacing the water drawn off was 20.5 ${ }^{\circ} \mathrm{C}$. The electrical power consumed during the heating cycles showed negligible fluctuation of 10-60 minutes during the heating cycles and the average was $1.32 \mathrm{~kW}$. There was an observable increase and decrease in the electrical power consumed during the first and the last 10 minutes of the heating cycles. The ambient temperature and relative humidity profiles were fairly constant, as shown, with averages of $19.7{ }^{\circ} \mathrm{C}$ and $79.8 \%$ respectively.

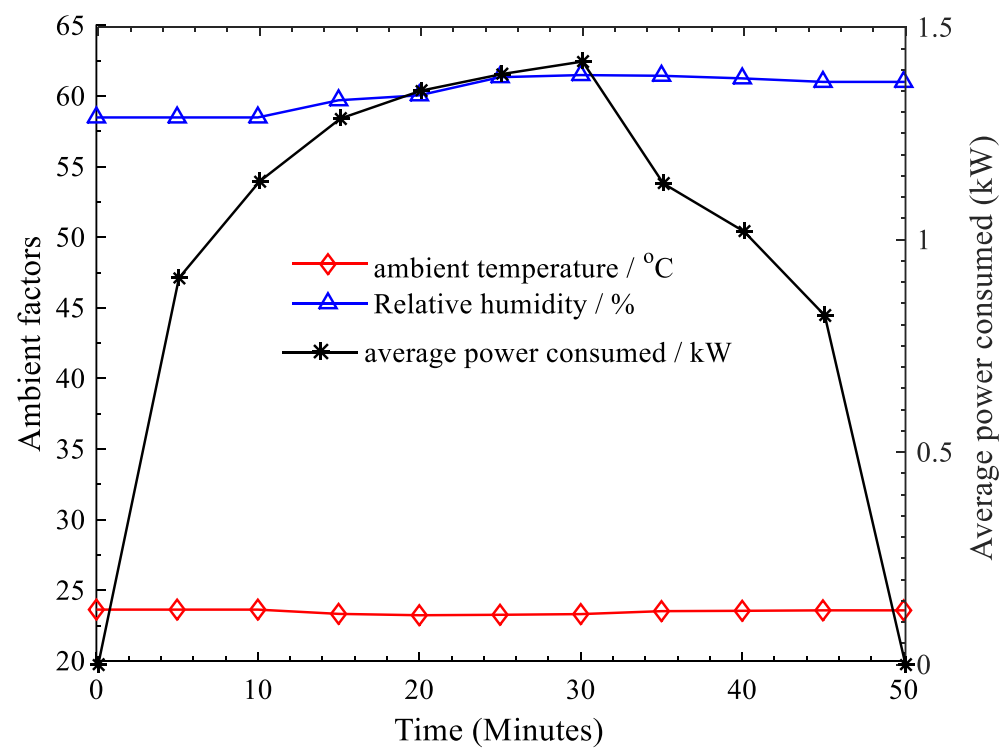

Figure 4: Variation of ambient factors and power consumed after $50 \mathrm{~L}$ of hot water was drawn off.

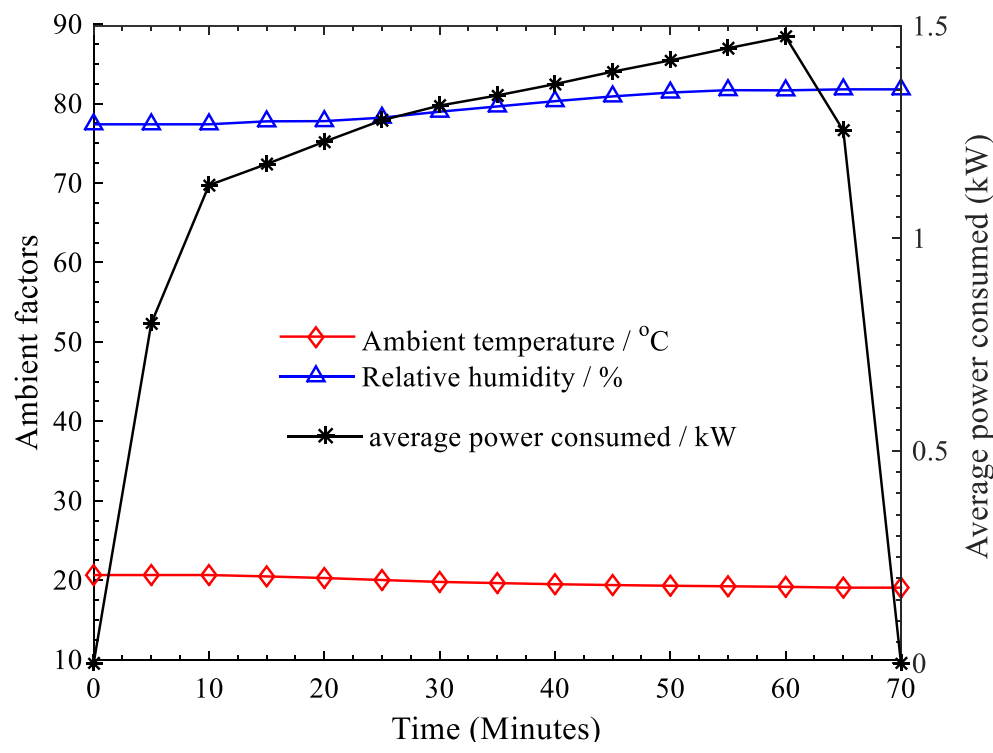

Figure 5: Variation of the ambient factors and power consumed after $100 \mathrm{~L}$ of hot water was drawn off. 


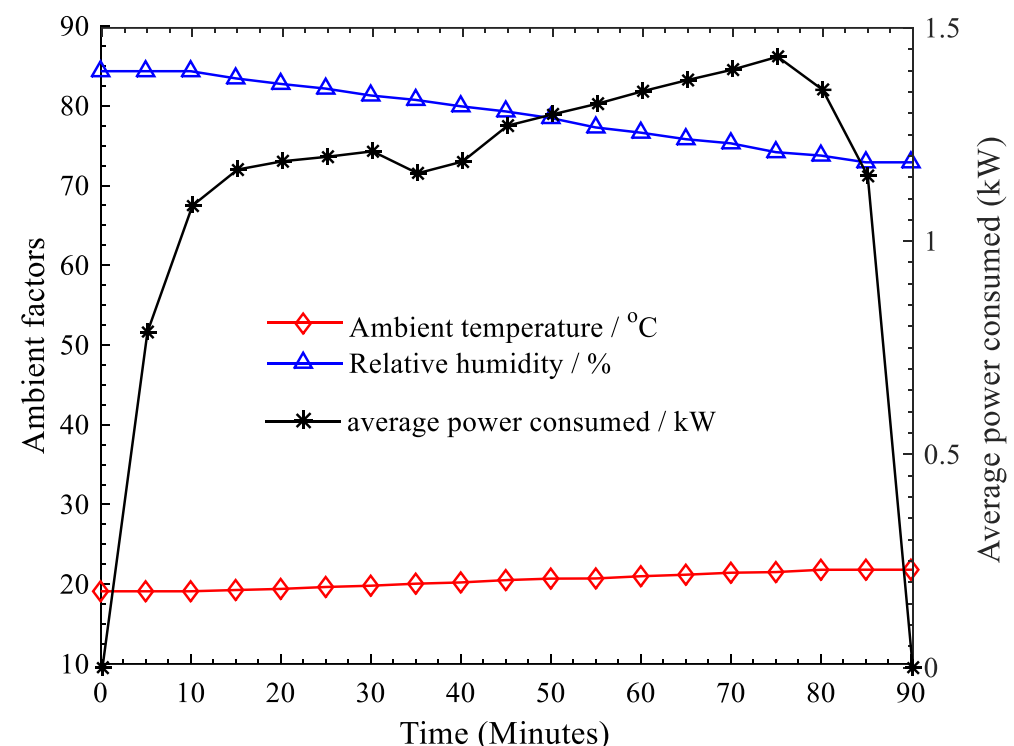

Figure 6: Variation of the ambient factors and power consumed after $150 \mathrm{~L}$ of hot water was drawn off.

\subsubsection{Power consumed and ambient weather profiles after 150 L hot water drawn off}

Figure 6 shows that it took 90 minutes to heat the stored water to the set point temperature $\left(55.0^{\circ} \mathrm{C}\right)$ after $150 \mathrm{~L}$ of hot water was drawn from the storage tank. The average temperature of the incoming cold water, substituting for the water drawn off, was $20.5^{\circ} \mathrm{C}$. The electrical power consumed during the heating cycle was practically constant between 10 and 80 minutes, averaging $1.26 \mathrm{~kW}$. There was a significant increase and decrease in the electrical power consumed during the first and last $10 \mathrm{~min}$ utes of the heating cycles. The ambient temperature and relative humidity profiles exhibited insignificant variation and the averages were $22.1^{\circ} \mathrm{C}$ and $78.0 \%$ respectively.

\subsection{A typical day demand and temperatures profiles of the refrigerant after specific volumes of hot water were drawn off}

The profiles of the power consumed by the AWHP and the temperatures of the refrigerant at the inlet and the outlet of the evaporator and the condenser after 50, 100 and $150 \mathrm{~L}$ of hot water drawn off were analysed. The electrical power consumption for the specific volumes of hot water drawn off was given above. The main focus was on the dynamics of the demand and the temperatures of the refrigerant at the designated locations on the ASHP unit during the VCRC initiated by the specific volumes of hot water drawn off.

6.2.1 Power consumed and the temperatures profiles of the refrigerant after $50 \mathrm{~L}$ of hot water drawn off Figure 7 shows that, during the VCRC due to $50 \mathrm{~L}$ of hot water drawn off, the electrical power consumed during the heating cycle (from 10 to 40 minutes after the start of the heating cycles) showed negligible variation, and the average was $1.24 \mathrm{~kW}$. The temperatures of the refrigerant in the evaporator and the condenser were not constant. Temperature gliding occurred at the evaporator and the condenser of the ASHP unit during the VCRC and it was attributed to the type of fluid (R417A) used in the unit, described as an azeotropic refrigerant. The temperature of the refrigerant at the inlet of the condenser was at maximum, and at minimum at the inlet of the evaporator. The temperature of the refrigerant at the inlet of the condenser varied between 65.0 and $75.0{ }^{\circ} \mathrm{C}$, averaging $70.0^{\circ} \mathrm{C}$. The temperature of the refrigerant at the outlet of the condenser ranged from 37.5 to 40.0 ${ }^{\circ} \mathrm{C}$, averaging $39.0{ }^{\circ} \mathrm{C}$. The difference between the average temperature of the refrigerant at the inlet and the outlet of the condenser was $31.0{ }^{\circ} \mathrm{C}$; the difference confirmed that high grade thermal energy was dissipated from the refrigerant in the condenser during the VCRC. On the other hand, the temperature of the refrigerant at the outlet of the evaporator varied between 25.0 and $32.0^{\circ} \mathrm{C}$, averaging $25.2{ }^{\circ} \mathrm{C}$. The temperature of the refrig-erant at the inlet of the evaporator ranged from 5.0 to 15.0 ${ }^{\circ} \mathrm{C}$, averaging $8.0{ }^{\circ} \mathrm{C}$. The difference between the average temperatures of the refrigerant at the outlet and the inlet of the evaporator was $17.2^{\circ} \mathrm{C}$, suggesting that low-grade thermal energy was absorbed by the refrigerant at the evaporator during the VCRC, from the ambient air (air in the vicinity of the evaporator). 


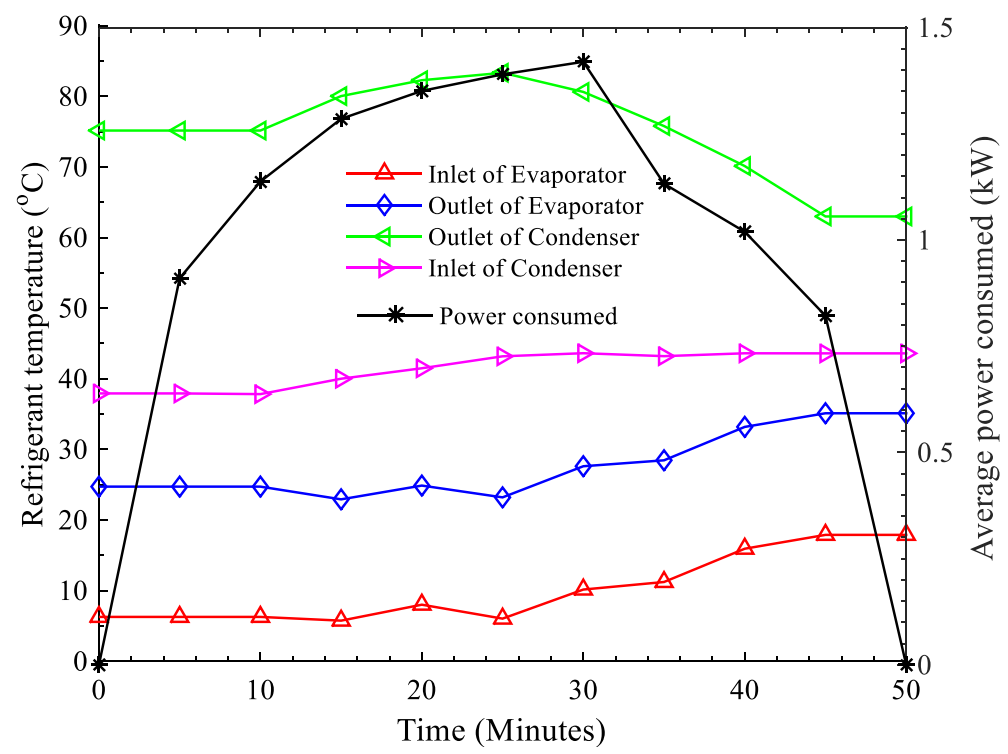

Figure 7: Refrigerant temperature and power consumed profiles after $50 \mathrm{~L}$ of hot water was drawn off.

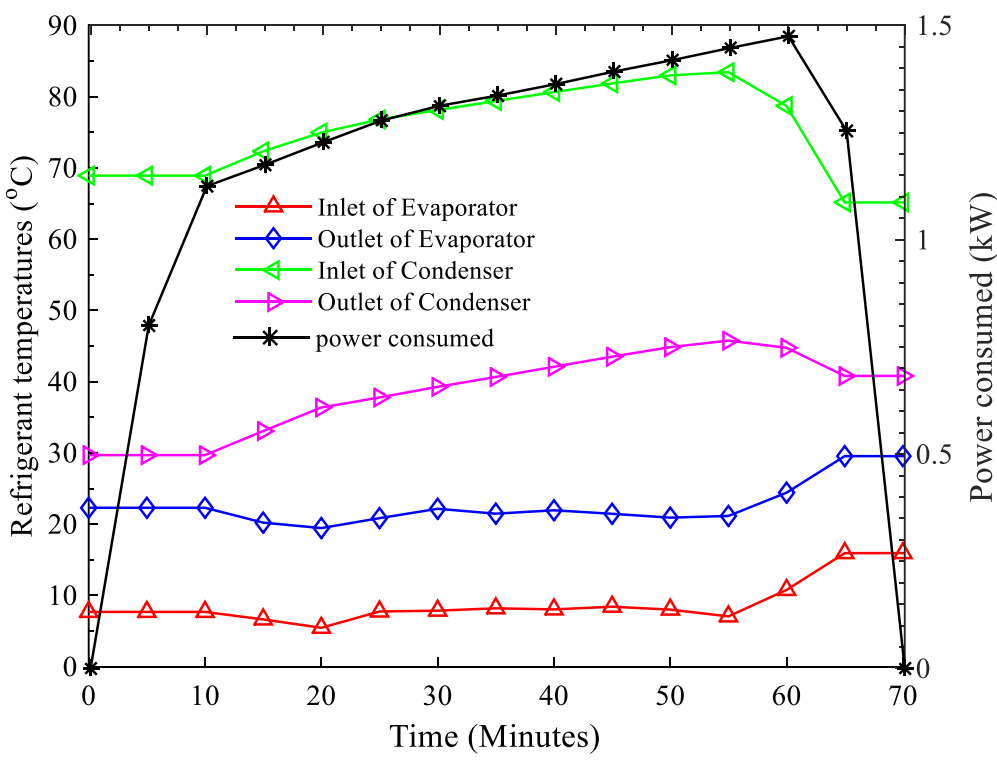

Figure 8: Refrigerant temperature and power consumed profiles after $100 \mathrm{~L}$ of hot water was drawn off.

6.2.2 Power consumed and the temperatures profiles of the refrigerant after $100 \mathrm{~L}$ hot water drawn off Figure 8 shows that during the VCRC due to $100 \mathrm{~L}$ of hot water being drawn off, the electrical power consumed during the heating cycles showed negligible fluctuation between 10 and 60 minutes, and the average was $1.32 \mathrm{~kW}$. The temperature of the refrigerant at the evaporator and the condenser revealed a gliding effect. The temperature of the refrigerant at the inlet of the condenser ranged from 60.0 to $75.0{ }^{\circ} \mathrm{C}$, averaging $72.0{ }^{\circ} \mathrm{C}$. The temperature of the refrigerant at the outlet of the condenser was between 30.5 and $40.8{ }^{\circ} \mathrm{C}$, averaging $35.0{ }^{\circ} \mathrm{C}$. The difference between the average temperatures of the refrigerant at the inlet and the outlet of the condenser was $37.0{ }^{\circ} \mathrm{C}$, which demonstrated that thermal energy was dissipated from the refrigerant at the condenser during the VCRC. Similarly, the temperature of the refrigerant at the outlet of the evaporator fluctuated between 20.0 and $25.0{ }^{\circ} \mathrm{C}$, averaging $22.0{ }^{\circ} \mathrm{C}$. The temperature of the refrigerant in the inlet of the evaporator ranged from 7.0 to $14.0{ }^{\circ} \mathrm{C}$, averaging $9.0{ }^{\circ} \mathrm{C}$. Furthermore, the difference between the average temperatures of the refrigerant at the outlet and the inlet of the evaporator was $13.0{ }^{\circ} \mathrm{C}$, which may indicate that low grade thermal energy was extracted from the ambient by the refrigerant at the evaporator during the VCRC. 
6.2.3 Power consumed and the temperature profiles of the refrigerant after $150 \mathrm{~L}$ hot water drawn off Figure 9 shows that during the VCRC associated with $150 \mathrm{~L}$ of hot water drawn off, the electrical power consumed during the heating cycles was practically constant between 10 and 80 minutes, and the average was $1.26 \mathrm{~kW}$. The temperature of the refrigerant in the evaporator and the condenser exhibited a gliding effect. The temperature of the refrigerant in the inlet of the condenser varied between 60.0 and $75.0{ }^{\circ} \mathrm{C}$, averaging $65.0{ }^{\circ} \mathrm{C}$. The temperature of the refrigerant at the outlet of the condenser ranged from 28.0 to $35.0{ }^{\circ} \mathrm{C}$, averaging $30.0^{\circ} \mathrm{C}$. The change in the average temperatures of the refrigerant at the inlet and the outlet of the condenser was $35.0{ }^{\circ} \mathrm{C}$. The temperature of the refrigerant in the outlet of the evaporator showed a variation between 18.0 and $23.0^{\circ} \mathrm{C}$, averaging 20.0 ${ }^{\circ} \mathrm{C}$. The temperature of the refrigerant in the inlet of the evaporator was between 5.0 and $12.0^{\circ} \mathrm{C}$, averaging $6.0^{\circ} \mathrm{C}$. The difference between the aver-age temperatures of the refrigerant at the outlet and the inlet of the evaporator was $14.0{ }^{\circ} \mathrm{C}$, demonstrating that thermal energy was harnessed from the ambient by the refrigerant at the evaporator during the VCRC.

\subsection{COP as a function of energy and the impact of the temperature of the refrigerant}

The temperature of the refrigerant at the inlet and the outlet of the evaporator and the condenser of the ASHP unit, the input electrical power consumed, the electrical energy consumed, the thermal energy gained and the derived coefficient of performance, in terms of the output and input energies (COPe) of the AWHP, were analysed for periods in summer (January to March 2018 and October to December
2018) and winter (April to July 2018), after 50, 100 and $150 \mathrm{~L}$ of hot water were drawn off.

\subsubsection{Summer performance of the COPe and the impact of the refrigerant temperatures}

Table 2 shows the minimum, maximum and average temperatures of the refrigerant at the inlet and outlet of the evaporator and the condenser, the electrical power consumed, the electrical energy consumed, the thermal energy gained, and the derived COPe during the VCRC following 50, 100 and $150 \mathrm{~L}$ of hot water drawn off. It can be seen from the table that the temperature of the refrigerant was lower at the inlet of the evaporator (with an average of $4 \circ \mathrm{C}$ ) than at the outlet of the evaporator (with an average of $27^{\circ} \mathrm{C}$ ), in all of the hot water drawn off scenarios. The difference between the refrigerant temperatures at the outlet and the inlet of the evaporator shows that both sensible and latent heat were gained by the refrigerant at the evaporator during the VCRC. Contrarily, the refrigerant temperature at the inlet of the condenser was higher (average of $79^{\circ} \mathrm{C}$ ) than at the outlet of the condenser (average of $39^{\circ} \mathrm{C}$ ). This difference shows that thermal energy was dissipated from the refrigerant at the condenser during the VCRC. The useful output thermal energy was the portion of the dissipated energy that was absorbed by the stored water, enabling it to attain the set point temperature during the VCRC. The power consumed throughout the heating cycles showed no significant difference over the different volumes of hot water drawn off and the average was $1.27 \mathrm{~kW}$. However, both the electrical energy consumed and the useful output thermal energy gained demonstrated a significant difference between the

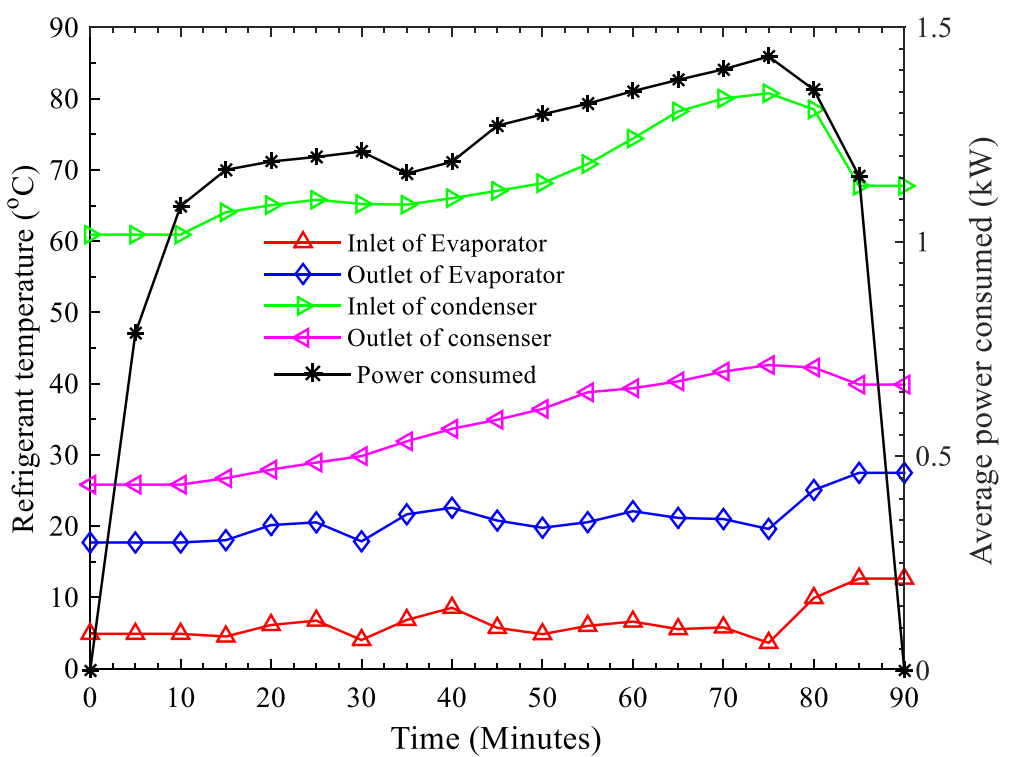

Figure 9: Refrigerant temperature and power consumption profiles after $150 \mathrm{~L}$ of hot water was drawn off. 
Table 2: Power, temperature and COPe for the specific volumes of hot water drawn off during summer

\begin{tabular}{lccc|ccc|ccc}
\hline & \multicolumn{3}{c|}{$\begin{array}{c}50 \text { L drawn off recorded } \\
\text { parameter values }\end{array}$} & \multicolumn{3}{c|}{$\begin{array}{c}\text { 100 } \\
\text { parameter values }\end{array}$} & \multicolumn{3}{c}{$\begin{array}{c}\text { 150 L drawn off recorded } \\
\text { parameter values }\end{array}$} \\
\cline { 2 - 10 } Parameters & Minimum & Maximum & Average & Minimum & Maximum & Average & Minimum & Maximum & Average \\
\hline Tevpi / ${ }^{\circ} \mathrm{C}$ & 4.02 & 7.03 & 4.93 & 4.94 & 3.93 & 3.82 & 2.81 & 5.11 & 4.07 \\
Tevpo / ${ }^{\circ} \mathrm{C}$ & 22.83 & 36.56 & 27.47 & 22.31 & 27.26 & 24.90 & 21.32 & 34.29 & 27.76 \\
Tconi / ${ }^{\circ} \mathrm{C}$ & 65.50 & 82.50 & 74.72 & 74.54 & 78.84 & 76.42 & 73.77 & 84.03 & 79.54 \\
Tcono / ${ }^{\circ} \mathrm{C}$ & 38.16 & 45.22 & 42.05 & 38.43 & 39.69 & 39.00 & 36.95 & 42.51 & 39.97 \\
$\mathrm{p} / \mathrm{kW}$ & 1.12 & 1.30 & 1.21 & 1.24 & 1.29 & 1.27 & 1.25 & 1.32 & 1.29 \\
$\mathrm{EE} / \mathrm{kWh}$ & 0.98 & 1.03 & 1.01 & 1.51 & 1.55 & 1.55 & 1.43 & 1.67 & 1.51 \\
$\mathrm{TE} / \mathrm{kWh}$ & 2.94 & 3.20 & 3.03 & 4.75 & 4.54 & 4.65 & 4.28 & 5.16 & 4.61 \\
$\mathrm{COPe}$ & 3.01 & 3.12 & 3.00 & 3.02 & 3.07 & 3.00 & 2.99 & 3.10 & 3.07 \\
\hline
\end{tabular}

Notes:

Tevpi = Refrigerant temperature at inlet of evaporator, Tevpo = Refrigerant temperature at outlet of evaporator,

Tconi $=$ Refrigerant temperature at inlet of condenser, Tcono = Refrigerant temperature at outlet of condenser,

$\mathrm{P}=$ average power consumed, $\mathrm{EE}=$ Electrical energy consumed, $\mathrm{TE}=$ Thermal energy consumed, $\mathrm{COPe}=\mathrm{COP}$ of ASHP water heater

Table 3: Power, temperature and COPe for the specific volumes of hot water drawn off during winter.

\begin{tabular}{lccc|ccc|ccc}
\hline & \multicolumn{3}{c|}{$\begin{array}{c}50 \text { L drawn off recorded } \\
\text { parameter values }\end{array}$} & \multicolumn{3}{c|}{$\begin{array}{c}\text { 100 L drawn off recorded } \\
\text { parameter values }\end{array}$} & \multicolumn{3}{c}{$\begin{array}{c}\text { 150 L drawn off recorded } \\
\text { parameter values }\end{array}$} \\
\cline { 2 - 9 } Parameters & Minimum & Maximum & Average & Minimum & Maximum & Average & Minimum & Maximum & Average \\
\hline Tevpi / ${ }^{\circ} \mathrm{C}$ & -0.42 & 7.64 & 4.03 & 3.20 & 4.51 & 4.13 & 2.95 & 5.98 & 4.58 \\
Tevpo / ${ }^{\circ} \mathrm{C}$ & 12.22 & 28.81 & 19.64 & 16.01 & 23.13 & 19.12 & 19.38 & 30.77 & 24.08 \\
Tconi / ${ }^{\circ} \mathrm{C}$ & 62.60 & 77.33 & 69.15 & 66.79 & 72.77 & 69.92 & 69.91 & 79.71 & 74.12 \\
Tcono / ${ }^{\circ} \mathrm{C}$ & 37.22 & 42.52 & 39.79 & 36.66 & 37.85 & 37.35 & 34.83 & 39.03 & 36.69 \\
$\mathrm{p} / \mathrm{kW}$ & 1.09 & 1.21 & 1.14 & 1.18 & 1.24 & 1.21 & 1.17 & 1.26 & 1.23 \\
$\mathrm{EE} / \mathrm{kWh}$ & 1.21 & 1.45 & 1.30 & 1.65 & 1.87 & 1.75 & 1.89 & 2.15 & 2.05 \\
$\mathrm{TE} / \mathrm{kWh}$ & 2.66 & 2.80 & 2.71 & 4.07 & 4.39 & 4.18 & 4.58 & 5.30 & 5.13 \\
$\mathrm{COPe}$ & 1.93 & 2.20 & 2.08 & 2.35 & 2.46 & 2.39 & 2.39 & 2.58 & 2.42 \\
\hline
\end{tabular}

Notes:

Tevpi = Refrigerant temperature at inlet of evaporator, Tevpo = Refrigerant temperature at outlet of evaporator,

Tconi $=$ Refrigerant temperature at inlet of condenser, Tcono $=$ Refrigerant temperature at outlet of condenser,

$\mathrm{P}=$ average power consumed, $\mathrm{EE}=$ Electrical energy consumed, $\mathrm{TE}=$ Thermal energy consumed, $\mathrm{COPe}=\mathrm{COP}$ of ASHP water heater

$50 \mathrm{~L}$ hot water drawn off (1.01 and $3.03 \mathrm{kWh})$, the $100 \mathrm{~L}(1.55$ and $4.66 \mathrm{kWh})$, and $150 \mathrm{~L}$ hot water drawn off (1.51 and $4.61 \mathrm{kWh}$ ). The average COPe of the AWHP for the different volumes of hot water drawn off, was 3.02 .

\subsubsection{Winter performance of the COPe and the impact of the refrigerant temperatures}

Table 3 presents the minimum, maximum and average temperatures of the refrigerant at the inlet and the outlet of the evaporator and the condenser, the electrical power consumed, the electrical energy consumed, the thermal energy gained and the derived COPe during the VCRC following 50, 100 and $150 \mathrm{~L}$ of hot water drawn off. The refrigerant temperature at the inlet of the evaporator (with an average of $4{ }^{\circ} \mathrm{C}$ ) was less than at the outlet of the evaporator (with an average of $21^{\circ} \mathrm{C}$ ) in all scenarios of hot water drawn off. The refrigerant temperature at the inlet of the condenser (with an average of $70{ }^{\circ} \mathrm{C}$ ) was higher than at the outlet (37 $\left.{ }^{\circ} \mathrm{C}\right)$. The difference in refrigerant temperature between the inlet and outlet of the evaporator and the condenser was slightly lower in winter than summer. The lower temperature of the refrigerant at the inlet and the outlet of the heat exchangers during the winter period was partly responsible for the decrease in COPe (compared to COPe during 
summer). Electrical power consumed throughout the heating cycles showed no significant difference, irrespective of the different volumes of hot water drawn off, and the average was $1.23 \mathrm{~kW}$. The electrical energy consumed and the thermal energy gained was significantly different between the $50 \mathrm{~L}$ hot water drawn off (1.30 and $2.80 \mathrm{kWh})$, and the $100 \mathrm{~L}$ (1.89 and $4.18 \mathrm{kWh}$ ), and $150 \mathrm{~L}$ hot water drawn off ( 2.05 and $5.13 \mathrm{kWh}$ ). The average COPe for the different volumes of hot water drawn off was 2.30 .

\subsection{COP as a function of the change in enthalpies and the impact of refrigerant pressure}

The refrigerant pressures obtained from the pressure sensors and the enthalpies derived from the saturation liquid-vapour table using REFPROP at the inlet and the outlet of the evaporator, the condenser, and the derived COP of the ASHP unit (COPt) were analysed for both the summer and winter periods under the scenarios of 50,100 and $150 \mathrm{~L}$ of hot water being drawn off.

\subsubsection{Summer performance of refrigerant pressure, enthalpies and the COPt}

Table 4 shows the minimum, maximum and average pressures and enthalpies of the refrigerant at the inlet and the outlet of the evaporator and the condenser of the ASHP unit, alongside the derived COPt during the VCRC, when 50, 100 and $150 \mathrm{~L}$ of hot water were drawn off. Table 4 shows that the average pressure of the refrigerant at the inlet of the evaporator was $0.53 \mathrm{MPa}$, almost equal to what it was at the outlet of the evaporator (with an average of $0.51 \mathrm{MPa}$ ) in all the hot water drawn off scenarios. The difference between the derived average enthalpy of the refrigerant at the outlet of the evaporator $(395.33 \mathrm{~kJ} / \mathrm{kg})$ and the inlet of the evaporator (285.71 kJ/kg) was $109.62 \mathrm{~kJ} / \mathrm{kg}$, as per the simulation, using the REFPROP software. Therefore, it can be seen that thermal energy was gained by the refrigerant at the evaporator during the VCRC. The average pressures of the refrigerant at the inlet and the outlet of the condenser was almost equal to $2.68 \mathrm{MPa}$. The difference between the average derived enthalpy of the refrigerant at the inlet of the condenser $(409.33 \mathrm{~kJ} / \mathrm{kg})$ and the outlet of the condenser $(259.33 \mathrm{~kJ} / \mathrm{kg})$ was 150 $\mathrm{kJ} / \mathrm{kg}$. It can be seen that thermal energy was dissipated from the refrigerant at the condenser during the VCRC. The average COPt of the ASHP unit for the different volumes of hot water drawn off was 3.52 and was higher than the corresponding COPe (3.02).

\subsubsection{Winter performance of the refrigerant pressures, enthalpies and the COPt}

Table 5 shows the minimum, maximum and average pressures and the derived enthalpies of the refrigerant at the inlet and the outlet of the evaporator and the condenser, and the derived COPt during the VCRC after 50,100 and $150 \mathrm{~L}$ hot water was drawn off. The average pressure of the refrigerant at the inlet of the evaporator was 0.53 $\mathrm{MPa}$, which was approximatelly equal to the average pressure of the refrigerant at the outlet of the evaporator (with an average of $0.51 \mathrm{MPa}$ ), with

Table 4: Pressure, enthalpy and COPt for the specific volumes of hot water drawn off during summer

\begin{tabular}{cccc|ccc|ccc}
\hline & \multicolumn{3}{c|}{$\begin{array}{c}50 \text { L drawn off recorded } \\
\text { parameter values }\end{array}$} & \multicolumn{3}{c|}{$\begin{array}{c}\text { 100 L drawn off recorded } \\
\text { parameter values }\end{array}$} & \multicolumn{3}{c}{$\begin{array}{c}\text { 150 L drawn off recorded } \\
\text { parameter values }\end{array}$} \\
\cline { 2 - 9 } Parameters & Minimum & Maximum & Average & Minimum & Maximum & Average & Minimum & Maximum & Average \\
\hline Pevpi / MPa & 0.53 & 0.58 & 0.53 & 0.52 & 0.51 & 0.51 & 0.49 & 0.54 & 0.53 \\
Pevpo / MPa & 0.50 & 0.55 & 0.50 & 0.51 & 0.50 & 0.50 & 0.45 & 0.52 & 0.50 \\
Pconi / MPa & 2.06 & 2.98 & 2.68 & 2.68 & 2.74 & 2.68 & 2.46 & 3.10 & 2.76 \\
Pcono / MPa & 1.95 & 2.87 & 2.57 & 2.57 & 2.63 & 2.57 & 2.35 & 3.00 & 2.69 \\
hevpi / kJ/kg & 277.85 & 291.66 & 289.36 & 287.78 & 288.86 & 288.16 & 277.37 & 292.27 & 278.90 \\
hevpo / kJ/kg & 390.00 & 400.00 & 395.00 & 392.00 & 401.00 & 395.00 & 390.00 & 400.00 & 396.00 \\
hconi / kJ/kg & 405.00 & 420.00 & 410.00 & 405.00 & 415.00 & 410.00 & 400.00 & 420.00 & 408.00 \\
hcono / kJ/kg & 250.00 & 265.00 & 265.00 & 258.00 & 260.00 & 260.00 & 250.00 & 261.28 & 253.40 \\
COPt & 3.49 & 3.62 & 3.48 & 3.50 & 3.56 & 3.52 & 3.47 & 3.59 & 3.55 \\
\hline
\end{tabular}

Pevpi = Refrigerant pressure at inlet of evaporator, Pevpo = Refrigerant pressure at outlet of evaporator, coni = Refrigerant pressure at inlet of condenser, Pcono = Refrigerant pressure at outlet of condenser, hevpi = Refrigerant enthalpy at inlet of evaporator, hevpo $=$ Refrigerant enthalpy at outlet of evaporator, hconi $=$ Refrigerant enthalpy at inlet of condenser, hcono $=$ Refrigerant enthalpy at outlet of condenser, $\mathrm{COPt}=\mathrm{COP}$ of ASHP unit 
Table 5: Pressure, enthalpy and COPt for the specific volumes of hot water drawn off during winter.

\begin{tabular}{|c|c|c|c|c|c|c|c|c|c|}
\hline \multirow[b]{2}{*}{ Parameter } & \multicolumn{3}{|c|}{$\begin{array}{l}50 \text { L drawn off recorded } \\
\text { parameter values }\end{array}$} & \multicolumn{3}{|c|}{$\begin{array}{c}100 \text { L drawn off recorded } \\
\text { parameter values }\end{array}$} & \multicolumn{3}{|c|}{$\begin{array}{l}150 \text { L drawn off recorded } \\
\text { parameter values }\end{array}$} \\
\hline & Minimum & Maximum & Average & Minimum & Maximum & Average & Minimum & Maximum & Average \\
\hline Pevpi / MPa & 0.46 & 0.58 & 0.53 & 0.49 & 0.53 & 0.49 & 0.53 & 0.54 & 0.53 \\
\hline Pevpo / MPa & 0.45 & 0.54 & 0.50 & 0.47 & 0.50 & 0.47 & 0.50 & 0.52 & 0.51 \\
\hline Pconi / MPa & 2.16 & 2.68 & 2.25 & 2.11 & 2.41 & 2.25 & 2.25 & 3.10 & 2.51 \\
\hline Pcono / MPa & 2.05 & 2.57 & 2.14 & 2.00 & 2.40 & 2.14 & 2.21 & 3.00 & 2.40 \\
\hline hevpi / kJ/kg & 245.29 & 259.56 & 251.67 & 248.55 & 254.67 & 251.22 & 251.45 & 261.24 & 255.49 \\
\hline hevpo / kJ/kg & 297.11 & 305.90 & 301.96 & 301.06 & 302.49 & 302.07 & 300.79 & 304.09 & 302.56 \\
\hline hconi / kJ/kg & 390.76 & 394.90 & 394.34 & 393.11 & 394.11 & 394.11 & 385.72 & 387.72 & 392.65 \\
\hline hcono / kJ/kg & 246.72 & 261.28 & 256.65 & 252.09 & 253.61 & 252.21 & 249.09 & 255.13 & 252.09 \\
\hline $\mathrm{COPt}$ & 2.23 & 2.55 & 2.42 & 2.72 & 2.85 & 2.77 & 2.78 & 2.81 & 2.99 \\
\hline
\end{tabular}

Pevpi $=$ Refrigerant pressure at inlet of evaporator, Pevpo $=$ Refrigerant pressure at outlet of evaporator, coni = Refrigerant pressure at inlet of condenser, Pcono = Refrigerant pressure at outlet of condenser, hevpi = Refrigerant enthalpy at inlet of evaporator, hevpo $=$ Refrigerant enthalpy at outlet of evaporator, hconi $=$ Refrigerant enthalpy at inlet of condenser, hcono $=$ Refrigerant enthalpy at outlet of condenser, $\mathrm{COPt}=\mathrm{COP}$ of ASHP unit

respect to the different volumes of hot water drawn off. The difference between the derived average enthalpy of the refrigerant at the outlet of the evaporator $(301.90 \mathrm{~kJ} / \mathrm{kg})$ and the inlet of the evaporator $(252.79 \mathrm{~kJ} / \mathrm{kg})$ was $49.11 \mathrm{~kJ} / \mathrm{kg}$. The average pressures of the refrigerant at the inlet and the outlet of the condenser was equal to $2.68 \mathrm{MPa}$. The difference between the average enthalpy of the refrigerant at the inlet of the condenser 393.70 $\mathrm{kJ} / \mathrm{kg}$ ) and the outlet of the condenser $(253.65$ $\mathrm{kJ} / \mathrm{kg}$ ) was $140.05 \mathrm{~kJ} / \mathrm{kg}$. The positive change in the enthalpy of the refrigerant at the inlet and the outlet of the condenser shows that thermal energy was dissipated at the condenser during the VCRC. The average COPt of the ASHP unit for the different volumes of hot water drawn off was 2.65 and was higher than the corresponding COPe (2.30).

\section{Conclusions}

We can conclude that the average annual COPt of the ASHP unit was 3.09 and was higher than the average annual COPe of the AWHP (2.66) by 0.43 . There was a significant difference between the annual COPt and the annual COPe. The COP of the ASHP unit and the AWHP depends strongly on the thermo-physical properties of the refrigerant and the design of the components that constitute the VCRC, as well as the ambient temperature. The average $\mathrm{COPe}, \mathrm{COPt}$, electrical power consumed, the difference in refrigerant temperature between the inlet and outlet of the condenser and the difference in refrigerant temperature between the outlet and inlet of the evaporator of the AWHP during the summer season were $3.02,3.52,1.27 \mathrm{~kW}, 40^{\circ} \mathrm{C}$ and 23 ${ }^{\circ} \mathrm{C}$; for the winter period, the corresponding figures were $2.30,2.65,1.23 \mathrm{~kW}, 40{ }^{\circ} \mathrm{C}$ and $17{ }^{\circ} \mathrm{C}$. Implementing efficient electric motors, with variable speed drives to operate the compressor, the water circulation pump and the propeller axial fan, will enhance both the COPe and the COPt of the ASHP system. The COPt will increase if the change in enthalpy of the refrigerant at the outlet and the inlet of the evaporator increases during the VCRC, while the change in enthalpy of the refrigerant at the inlet and the outlet of the condenser remains the same. The average annual input electrical power consumed by the ASHP unit was $1.09 \mathrm{~kW}$ and was $12.8 \%$ lower than the average annual input electrical power consumed by the AWHP, which was 1.25 $\mathrm{kW}$. The corresponding change in enthalpy of the refrigerant in the condenser, was $145.03 \mathrm{~kJ} / \mathrm{kg}$ and was greater than that of the evaporator $(79.37$ $\mathrm{kJ} / \mathrm{kg}$ ) for the different volumes of hot water drawn off.

\section{Acknowledgement}

The authors acknowledge the Central University of Technology, in Free State, South Africa for financial support toward the acquisition of the research equipment.

\section{Author contributions}

S. Tangwe - conceptualisation, drafting and development of the manuscript.

K. Kusakana - technical input, technical restructuring and proofreading of the manuscript. 


\section{References}

[1] Swan, L.G. and Ugursal, V.I., 2009. Modeling of end-use energy consumption in the residential sector: A review of modeling techniques. Renewable and Sustainable Energy Reviews, 13(8): 1819-1835.

[2] Rousseau, P.G. and Greyvenstein, G.P., 2000. Enhancing the impact of heat pump water heaters in the South African commercial sector. Energy, 25(1): 51-70.

[3] Tangwe, S., Simon, M. and Meyer, E., 2014. Mathematical modeling and simulation application to visualize the performance of retrofit heat pump water heater under first hour heating rating. Renewable Energy, 72: 203-211.

[4] Chua, K.J., Chou, S.K. and Yang, W.M., 2010. Advances in heat pump systems: A review. Applied Energy, 87(12): 3611-3624.

[5] Hepbasli, A. and Kalinci, Y., 2009. A review of heat pump water heating systems. Renewable and Sustainable Energy Reviews, 13(6-7): 1211-1229.

[6] Morrison, G.L., Anderson, T. and Behnia, M., 2004. Seasonal performance rating of heat pump water heaters. Solar Energy, 76(1-3): 147-152.

[7] Bodzin, S., 1997. Air-to-water heat pumps for the home. Home Energy, 14(4):1-120 .

[8] Xu, G., Zhang, X. and Deng, S., 2006. A simulation study on the operating performance of a solar-air source heat pump water heater. Applied Thermal Engineering, 26(11-12): 1257-1265.

[9] Peng, J.W., Li, H. and Zhang, C.L., 2016. Performance comparison of air-source heat pump water heater with different expansion devices. Applied Thermal Engineering, 99: 1190-1200.

[10] Tangwe, S.L., Simon, M. and Mhundwa, R., 2018. The performance of split and integrated types air-source heat pump water heaters in South Africa. Journal of Energy in Southern Africa, 29(2): 12-20.

[11] Kamel, R.S., Fung, A.S. and Dash, P.R., 2015. Solar systems and their integration with heat pumps: A review. Energy and Buildings, 87: 395-412.

[12] Staffell I, Brett D, Brandon N, Hawkes A., 2012. A review of domestic heat pumps. Energy \& Environmental Science. 5(11): 9291-306.

[13] Vieira, A.S., Stewart, R.A. and Beal, C.D., 2015. Air source heat pump water heaters in residential buildings in Australia: Identification of key performance parameters. Energy and Buildings, 91: 148-162.

[14] Guo, X. and Goumba, A.P., 2018. Air source heat pump for domestic hot water supply: Performance comparison between individual and building scale installations. Energy, 164: 794-802.

[15] Ashdown, B.G., 2004. Heat pump water heater technology: Experiences of residential consumers and utilities (No. ORNL/TM-2004/81).

[16] Sinha, S.K. and Dysarkar, A., 2008. United States patent application: Heat pump liquid heater. Available on http://appft1. uspto. gov/netacgi/nphas on: 19-04.

[17] Lemmon, E.W., Huber, M.L. and McLinden, M.O., 2010. NIST Standard Reference Database 23, Reference Fluid Thermodynamic and Transport Properties (REFPROP), version 9.0, National Institute of Standards and Technology. R1234yf. fld file dated December, 22: 2010.

[18] De Monte, F., 2002. Calculation of thermodynamic properties of R407C and R410A by the Martin-Hou equation of state - Part II: Technical interpretation. International Journal of Refrigeration, 25(3): 314-329.

[19] De Swartdt, C.A., Meyer, J.P. 2001. A performance comparison between an air source and a ground source reversible heat pump. International Journal of Energy Research, 25: 899-910.

[20] Urchueguía, J.F., Zacarés, M., Corberán, J.M., Montero, A., Martos, J. and Witte, H., 2008. Comparison between the energy performance of a ground coupled water to water heat pump system and an air to water heat pump system for heating and cooling in typical conditions of the European Mediterranean coast. Energy Conversion and Management, 49(10): 2917-2923.

[21] Congedo, P.M., Baglivo, C., Bonuso, S. and D'Agostino, D., 2020. Numerical and experimental analysis of the energy performance of an air-source heat pump (ASHP) coupled with a horizontal earth-to-air heat exchanger (EAHX) in different climates. Geothermics, 87: 101845.

[22] Wang, X., Xia, L., Bales, C., Zhang, X., Copertaro, B., Pan, S. and Wu, J., 2020. A systematic review of recent air source heat pump (ASHP) systems assisted by solar thermal, photovoltaic and photovoltaic/thermal sources. Renewable Energy, 146: 2472-2487. 